\title{
Cellular Therapies in Onco-Hematology: 60 Years of Progress
}

\author{
Oscar Borsani* \\ Department of Molecular Medicine, University of Pavia, Italy \\ *Corresponding author: Oscar Borsani, Department of Molecular Medicine, University of Pavia, Pavia, Italy
}

\section{Introduction}

In the last years, CAR-T cell therapy gained the attention of the entire scientific community thanks to their high rate of efficacy in some hematological and non-hematological malignancies. However, the scientific bases of this innovative therapy should be traced back to the mid-90s, when animal models gave the first evidences concerning the protective role of $\mathrm{T}$ cell immunity against cancer. In 1956, the potential anti-tumor efficacy of bone marrow transplantation was suggested by results from murine models of leukemia treated with supralethal irradiation and subsequent marrow grafting [1]. However, the first clinical evidence about the anti-cancer activity of allogeneic bone marrow transplantation was given by Thomas E.D. who, in 1959, described the first successful marrow grafting in two leukemic patients who received supralethal irradiation and subsequent bone marrow transplantation by identical twin donors [2]. However, despite first descriptions of the Human Leukocyte Antigen (HLA) by [3,4], it took more than 10 years to successfully perform allogenic bone marrow transplantation from non-twins' donors. In 1961, in a two-page preliminary communication, the immunologist Jacques Miller demonstrated that early thymectomised mice developed a severe lymphocyte depletion and immune disfunction in adult age, thereby providing the first evidences about the role of thymus gland in normal $\mathrm{T}$ cell development and immune system function [5]. In 1986, Steven Rosenberg studied the adoptive transfer of tumor-infiltrating lymphocytes (TIL) in mice bearing hepatic and pulmonary metastasis of colon adenocarcinoma, demonstrating a strong synergistic effect when associated with the administration of cytotoxic chemotherapy [6]. In the following years, a bulk of clinical evidences further confirmed that immune cells can fight cancer. Nowadays, it is well known that the efficacy of allogeneic bone marrow transplantation depends on both the cytotoxicity provided by high dose chemotherapy (i.e. the conditioning regimen) as well as on the anti-neoplastic effect of transplanted immune cells (i.e. graft-versus-leukemia (GvL) effect). For these reasons, the allogeneic bone marrow transplantation may be considered as the first example of cellular therapy in the history of anticancer treatments.

Further evidences concerning the anti-tumor role of $\mathrm{T}$ cells in transplanted patients came from the recent demonstration that those patients who develop mild to moderate chronic graftversus-host disease (cGvHD), an undesirable process sustained by donors' $\mathrm{T}$ cells, have lower recurrence rates of the underlying malignancy after bone marrow transplantation [7]. Other evidences demonstrated that the overall survival (OS) of patients transplanted for malignant diseases developing mild cGVHD is better compared to patients without cGVHD. Even OS of patients with moderate cGVHD is not different from patients without cGVHD, as the slightly increased mortality associated with cGVHD is counterbalanced by lower disease-associated mortality [8]. According to these results, in the context of bone marrow transplantation, $\mathrm{T}$ cells may be seen as the leading actors of both the protective (i.e. GvL effect) and detrimental (i.e. GvHD) cellular processes which characterize the allogeneic bone marrow transplantation procedure. The dualedged role played by $\mathrm{T}$ lymphocytes spurred a search to identify and separate beneficial and deleterious $\mathrm{T}$ cells, which spawned allogeneic therapies such as donor leukocyte infusion [9] and virus-specific T cell therapy [10-12]. Altogether, these early clinical investigations eventually pointed to the need to better control the composition of therapeutic $\mathrm{T}$ cell products by increasing their content of tumour-specific $\mathrm{T}$ cells and removing $\mathrm{T}$ cells with harmful potential.

In 1990, the emergence of replication-defective viral vectors provided new hints for cellular therapies based on genetically modified $\mathrm{T}$ lymphocytes [13]. Taking advantage from this new technology, in 1992 the young immunologist Michel Sadelain 
pioneered the use retroviral vectors to genetically engineer human T cells [14]. Two years later, the immunologist Zelig Eshhar from the Weizman Institute in Israel, exploited the same technology to engineers $\mathrm{T}$ cells with the first chimeric molecule, produced by fusion of the antigen-binding portion of an antibody to the intracellular part of a $\mathrm{T}$ cell receptor. This new chimeric antigen receptor (CAR) became known as first-generation CARs. However, despite its technological innovation, these first-generation CARs did not persist in the body and were not clinically effective [15]. In order to overcome this issue, in 1998 Dr. Sadelain and his colleagues demonstrated that introducing a co-stimulatory molecule (e.g. CD28) into the structure of CAR of engineered T cells allows them to persist and remain active in the body, thus setting the stage for a new generation of CARs (i.e. second-generation CARs) [16]. Starting from this new discovery, a research team from the Memorial Sloan Kettering (MSK) Cancer Center built the first effective CAR T cells, directed against a prostate cancer antigen, demonstrating that these second-generation CARs $\mathrm{T}$ cells were able to survive, proliferate and kill prostate cancer cells in vitro and establishing the feasibility of CAR T cell therapy [17]. It was in 2003 the first description of human CAR T cells directed against CD19, which demonstrated the ability to kill leukemia cells in a mouse model. This was the first time that CD19 was shown as a feasible target for CAR T cells [18].

In 2009, Dr. Sadelain and colleagues published the detailed description of their manufacturing process for CD19 CAR T cells production starting from $\mathrm{T}$ cells derived patients with chronic lymphocytic leukemia (CLL). This description opened the way to the first phase I clinical trials involving CAR $\mathrm{T}$ cells in patients with chemo-refractory CLL and in patients with relapsed acute lymphoblastic leukemia (ALL) [19]. In 2012 the Cancer Research Institute bestowed the Coley Award for Tumor Immunology to both Dr. Michel Sadelain, from the MSK Cancer Center, and Dr. Carl June of the University of Pennsylvania, for their eminent work in CAR T cells development. In 2013 results from the first clinical trial using CD19 CAR T cells in adults with chemo-refractory ALL were published, demonstrating rapid tumor eradication and achievement of MRD- complete remissions in all treated patients [20]. In 2014, the FDA designated the CD19-directed CAR T cell therapy as "breakthrough" therapy, signaling the field's scientific and clinical progress. Given the recognized high efficacy of antiCD19 CAR T cell therapy, it didn't take long before CAR T cells against other tumor-associated antigens were developed. In 2014 the first results on CARs built to recognize the mesothelin, a cellsurface antigen implicated in tumor invasion and highly expressed in several solid tumor such as mesothelioma, pancreas, ovarian, breast and lung cancer, were published [21]. The production of a new generation of CARs, so-called "armored CARs" (i.e. autologous $\mathrm{T}$ cells genetically engineered to secrete cytokine such as IL-12 upon antigen recognition), opened the way to the first phase I study of immunotherapy with armored CARs directed against the MUC16ecto antigen to treat recurrent high-grade serous ovarian, fallopian tube or primary peritoneal cancer (NCT02498912I), which is actually recruiting.

In 2017, the first CARs crossed the regulatory finish line, as the FDA approved CD19-directed T cells for the treatment of relapsed, refractory ALL in children and young adults.

In 2018, Dr. Sadelain and colleagues demonstrated that new engineering modalities, based on targeted nucleases like CRISPR, can be used to place a CAR at a specific genetic location in T cells, improving the manufacturing process and further enhancing the efficacy and safety of CAR T cells [22]. Nowadays, CAR T cell therapy represent one of the most popularly cited scientific advance, since it offers a further hope to our patients. However, we should attempt to remind that this leading discovery has been made possible by multiple little advances started more than 50 years ago. Like it has been said by the famed Isaac Newton "If I saw further than other men, it was because I stood on the shoulders of giants", our advances are made by thousands of little pieces of knowledge added by the perseverance and love of science of several eminent scientists.

\section{References}

1. DWH Barnes, MJ Corp, JF Loutit, FE Neal (1956) Treatment of murine leukaemia with $\mathrm{X}$ rays and homologous bone marrow; preliminary communication. Br Med J 2(4993): 626-627.

2. Thomas ED, Lochte HL JR, Cannon JH, Sahler OD, Ferrebee JW (1959) Supralethal whole body irradiation and isologous marrow transplantation in man. J Clin Invest 38: 1709-1716.

3. Dausset J (1958) Iso-leuko-antibodies. Acta Haematol 20(1-4): 156-166.

4. Van Rood JJ, JG Eernisse, A Van Leeuwen (1958) Leucocyte antibodies in sera from pregnant women. Nature 181(4625): 1735-1736.

5. Miller JF (1961) Immunological function of the thymus. Lancet 2(7205): 748-749.

6. Rosenberg SA, P Spiess, R Lafreniere (1986) A new approach to the adoptive immunotherapy of cancer with tumor-infiltrating lymphocytes. Science 233(4770): 1318-1321.

7. Grube M, Holler E, Weber D, Holler B, Herr W, et al. (2016) Risk Factors and Outcome of Chronic Graft-versus-Host Disease after Allogeneic Stem Cell Transplantation-Results from a Single-Center Observational Study. Biol Blood Marrow Transplant 22(10): 1781-1791.

8. Carreras E (2019) The EBMT Handbook.

9. Kolb, HJ, Schattenberg A, Goldman JM, Hertenstein B, Jacobsen N, et al. (1995) Graft-versus-leukemia effect of donor lymphocyte transfusions in marrow grafted patients. Blood 86(5): 2041-2050.

10. Riddell SR, PD Greenberg (1995) Principles for adoptive T cell therapy of human viral diseases. Annu Rev Immunol 13: 545-586.

11. Papadopoulos EB, Ladanyi M, Emanuel D, Mackinnon S, Boulad F, et al. (1994) Infusions of donor leukocytes to treat Epstein-Barr virusassociated lymphoproliferative disorders after allogeneic bone marrow transplantation. N Engl J Med 330(17): 1185-1191.

12. Heslop HE, MK Brenner, CM Rooney, (1994) Donor T cells to treat EBVassociated lymphoma. N Engl J Med 331(10): 679-680.

13. Miller AD (1990) Retrovirus packaging cells. Hum Gene Ther 1(1): 5-14. 
14. Cinader B, RG Miller (2014) Progress in Immunology VI: Sixth International Congress of Immunology Elsevier pp. 1174.

15. Eshhar Z, Waks T, Gross G, Schindler DG (1993) Specific activation and targeting of cytotoxic lymphocytes through chimeric single chains consisting of antibody-binding domains and the gamma or zeta subunits of the immunoglobulin and T-cell receptors. Proc Natl Acad Sci USA 90(2): 720-724.

16. Krause A, Guo HF, Latouche JB, Tan C, Cheung NK, et al. (1998) Antigendependent CD28 signaling selectively enhances survival and proliferation in genetically modified activated human primary T lymphocytes. J Exp Med 188(4): 619-626.

17. Maher J, Brentjens RJ, Gunset G, Rivière I, Sadelain M (2002) Human T-lymphocyte cytotoxicity and proliferation directed by a single chimeric TCRzeta /CD28 receptor. Nat Biotechnol 20(1): 70-75.

18. Brentjens RJ, Latouche JB, Santos E, Marti F, Gong MC, et al. (2003) Eradication of systemic B-cell tumors by genetically targeted human $\mathrm{T}$ lymphocytes co-stimulated by CD80 and interleukin-15. Nat Med 9(3): 279-286.
19. Hollyman, D, Stefanski J, Przybylowski M, Bartido S, Borquez Ojeda 0 , et al. (2009) Manufacturing validation of biologically functional T cells targeted to CD19 antigen for autologous adoptive cell therapy. J Immunother 32(2): 169-180.

20. Brentjens RJ, Davila ML, Riviere I, Park J, Wang X, et al. (2013) CD19targeted $\mathrm{T}$ cells rapidly induce molecular remissions in adults with chemotherapy-refractory acute lymphoblastic leukemia. Sci Transl Med 5(177): 177.

21. Adusumilli PS, Cherkassky L, Villena Vargas J, Colovos C, Servais E, et al. (2014) Regional delivery of mesothelin-targeted CAR T cell therapy generates potent and long-lasting CD4-dependent tumor immunity. Sci Transl Med 6(261): 261.

22. Perales MA Kebriaei P, Kean LS, Sadelain M (2017) Reprint of: Building a Safer and Faster CAR: Seatbelts, Airbags, and CRISPR. Biol Blood Marrow Transplant 24(3S): S15-S19.

\section{(c) (1) \\ This work is licensed under Creative Commons Attribution 4.0 License}

To Submit Your Article Click Here:

Submit Article

DOI: $10.32474 /$ OAJOM.2020.03.000167

\section{OAJOM}

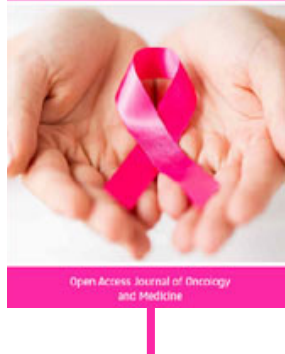

\section{Open Access Journal of Oncology and Medicine}

\section{Assets of Publishing with us}

- Global archiving of articles

- Immediate, unrestricted online access

- Rigorous Peer Review Process

- Authors Retain Copyrights

- Unique DOI for all articles 